\title{
Los Hechos Históricos de la Transición Democrática Chilena en las Aulas de Educación Secundaria
}

The Historical Facts of the Chilean Democratic Transition in Secondary Education Classrooms

Gabriela Vásquez Leyton*

María Sánchez Agustí**

Nelson Vásquez Lara ${ }^{* * *}$

\section{RESUMEN}

Fueron más de tres millones de chilenos los que, mediante su voto, dijeron "no" al régimen de Augusto Pinochet, poniendo fin a los años de Dictadura. Por ello, la Transición a la Democracia es uno de los procesos más controversiales de la historia reciente chilena, determinando las relaciones que se desarrollan actualmente. En el presente artículo, se exponen parte de los resultados de una investigación cuyo objetivo es conocer las ideas de los estudiantes de secundaria chilena sobre el proceso transicional y cómo se desarrolla su aprendizaje en el mundo escolar. El estudio de carácter cuali-cuantitativo se realizó a partir de los discursos de estudiantes de secundaria chilena de centros educativos provenientes de 4 las ciudades más importan-

\section{Abstract}

They were more than three million Chileans who, by their vote, said "no" to the regime of Augusto Pinochet, ending the years of Dictatorship. Therefore, the Transition to Democracy is one of the most controversial processes in Chilean recent history, determining the relationships that are currently developing. In the present article, part of the results of a research is exposed whose objective is to know the ideas of the Chilean secondary students about the transitional process and how their learning is developed in the school world. The study of qualitative-quantitative character was made from the discourses of Chilean high school students from educational centers from the most important cities of

\footnotetext{
* Doctora en Didáctica de la Historia. Profesora de la Pontificia Universidad Católica de Valparaíso. Valparaíso, Chile. gabriela.vasquez@pucv.cl

** Doctora en Didáctica de las Ciencias Sociales. Profesora en la Universidad de Valladolid. Valladolid, España. almagosa@sdcs.uva.es

*** Doctor en Didáctica de la Historia. Profesor de la Pontificia Universidad Católica de Valparaíso.Valparaíso, Chile.nelson.vasquez@pucv.cl
} 
tes del país (La Serena, Valparaíso, Santiago y Concepción). Estas ideas se recogen a partir un cuestionario de preguntas abiertas y cerradas analizadas a través del programa estadístico informático. En esta instancia analizaremos sus declaraciones sobre los hechos que relevan de la Transición chilena y los temas históricos tratados en las clases de historia, donde el estudiantado destaca el valor de los ciudadanos como agentes de cambio que, a través de sus movilizaciones y del derecho a sufragio son los que derriban a la Dictadura.

Palabras claves: didáctica de la Historia; Historia reciente; transición democrática; concepciones de estudiantes; temas controversiales. the country (La Serena, Valparaíso, Santiago and Concepción). These ideas are collected from a questionnaire of open and closed questions analyzed through the computer statistical program. In this instance we will analyze your statements about the events that arise from the Chilean Transition and the historical issues dealt with in the history classes, where the student highlights the value of citizens as agents of change who, through their mobilizations and the right to suffrage are those that overthrow the Dictatorship.

Keywords: didactics of History; recent History; democratic transition; conceptions of students; controversial issues.

El Golpe militar en Chile, fue el hecho que culminó el proceso de deterioro de la convivencia cívica y de erosión transversal en los valores democráticos y republicanos que habían sustentado la vida política nacional desde al menos 1932 (Faúndez, 2013), y que inicia una cruenta dictadura que mantendría a Pinochet 17 años en el poder ejecutivo del Estado chileno. Cada aniversario trae consigo una serie de especiales periodísticos que desde distintas visiones, posturas e ideas, buscan ayudar en la creación de una "Conciencia histórica" en los ciudadanos que vivieron en dictadura y que hoy viven en democracia, así como en los que somos hijos de la democracia pero que aún percibimos los efectos de dicho proceso histórico.

Frente al gran revuelo mediático de esta conmemoración, ${ }^{1}$ que tiene su explicación en la consolidación de los canales democráticos que han ido madurando a los ciudadanos chilenos, creemos que hoy más que nunca esta investigación tiene plena vigencia y real sentido. Si bien es cierto que en este trabajo no estudiamos la Dictadura, si estudiamos ese otro proceso histórico denominado Transición Democrática, que nos trajo consigo una serie de valores que hoy en Democracia se desarrollan plenamente, tales como el diálogo 
y la búsqueda de acuerdos, así como también la libertad y los derechos de todos los ciudadanos. Entendemos que:

La Transición nos sirve para educar en Democracia a nuestros jóvenes. Ella permite enseñar que la Democracia no llega como algo natural después de la Dictadura, como sale el sol tras la tormenta, sino que es una conquista que sólo se produce cuando una sociedad lucha por conseguirla, superando todas las dificultades, y permanece vigilante en su práctica cotidiana y en su defensa permanente. (González Gallego, 2011, p.9)

$\mathrm{Al}$ respecto, una enseñanza de la Historia basada en los principios que permiten fortalecer una ciudadanía democrática, tiene mucho que contribuir. Como ya sabemos, en el siglo XIX el naciente estado burgués-liberal buscó a través de la educación fortalecer su proyecto nacional; a través de la enseñanza de la historia se pretendía racionalizar y homogenizar a la sociedad en función del concepto de nación (Iglesias, 2009). Pero hoy, además, la escuela debe fortalecer los principios de la vida en democracia, fortaleciendo la participación activa de todos los actores, y desarrollar prácticas que tengan como base en su actuar el respeto de los derechos humanos, la defensa de la libertad como un valor intrínseco del ser humano, para así construir una sociedad más justa, más tolerante.

\section{MARCO TEÓRICO}

Como consecuencia de las transiciones a la democracia en el sur de Europa, y en particular en España, a mediados de los años setenta el tema de las transiciones democráticas se transformó en un objeto preferente en la investigación de los científicos políticos o de la sociología política. Esta preocupación se mantuvo en el tiempo como consecuencia de los procesos de democratización en América Latina, Europa del Este e incluso en algunos casos asiáticos. A pesar de esta tendencia, el tema estuvo por muchos años fuera de la atención de los historiadores. Actualmente, esta situación ha sido paliada con la aparición de diversas investigaciones históricas que han mostrado la complejidad de este tipo de procesos que, en general, sólo de manera limitada, pueden ser descritos con patrones comunes ya que un exceso de modelización oculta la dificultad del análisis de las particularidades que tiene todo proceso 
histórico. Estos trabajos tienen por objetivo clarificar el conocimiento de aquellos hechos, contradictorios en ocasiones y confusos en su desarrollo (Tusell; Soto, 1996).

Desde un ámbito político, debemos entender que el concepto de Transición hace referencia al intervalo que se extiende entre un régimen político y otro tipo de régimen, así las transiciones pueden ser delimitadas, por el inicio del proceso de disolución del régimen autoritario y por el establecimiento de otro régimen que puede ser alguna forma de Democracia, o eventualmente el surgimiento de alguna alternativa revolucionaria. La característica principal de estos procesos de Transición se relaciona con que en su transcurso las reglas del juego político no están claramente definidas y, por ello, son objeto de contienda entre diferentes actores políticos, debido a que los éstos no sólo luchan por satisfacer sus intereses de corto plazo, y eventualmente la de aquellos sectores sociales que representan, sino que también combaten por definir las normas y procedimientos que configurarán el futuro sistema político. Estas normas suelen ser un campo de disputa en donde los gobernantes autoritarios, que conservan el control del Estado, aspiran a conservar un poder discrecional sobre el nuevo ordenamiento jurídico (O’Donnell; Schmitter, 1998).

La forma en que se desarrolla el paso desde la dominación autoritaria hacia el sistema democrático está determinada por circunstancias históricas de cada proceso, que aunque en cada país son únicas, pueden configurar algunas pautas o criterios comunes de análisis tales como; la manera en que se produce la crisis y el colapso del régimen democrático anterior; la naturaleza, el desarrollo y la duración del período autoritario; los medios a que apeló el régimen de facto a fin de ganar legitimidad y maniobrar frente a las amenazas que pusieron en peligro su férreo poder; la iniciativa política y la oportunidad con que se emprendieron los movimientos tentativos hacia la apertura; el grado de seguridad y de autoconfianza que revelan las élites del régimen, así como la confianza y aptitudes de quienes pretenden abrir el proceso político; la naturaleza de la coyuntura económica, el marco internacional en que se desarrolla; $y$, finalmente, las "modas" intelectuales en el campo internacional, que otorgan legitimidad a ciertas formas de Transición y no a otras (O’Donnell; Schmitter, 1998).

Debemos considerar el hecho que no existe posibilidad de Transición cuyo inicio no sea, en primer lugar, una crisis del régimen político autoritario que puede ser de naturaleza multicausal (crisis económicas, problemas 
sucesorios, conflictos externos, etc.) y, en segundo lugar, de las divisiones dentro de la coalición gobernante entre conservadores y reformistas, es decir, entre las personas que presentan visiones de continuidad y cambio respecto a la forma de organizar el país. Por último, en la mayoría de los casos (también hay transiciones por colapso del régimen como fue en el caso de la Dictadura Argentina) la Democracia sólo es una alternativa posible a través de un compromiso o alianza entre elites políticas y sociales, quienes generan los acuerdos y los consensos sobre el futuro. Este "pacto" se ha convertido en el elemento crucial tanto del éxito de las transiciones como de sus análisis intelectuales posteriores (O’Donnell; Schmitter, 1998).

A nivel internacional, existieron algunos factores que propiciaron la denominada "Tercera Ola” (Huntington, 1992), situación referida a la crisis de los regímenes autoritarios y a la valoración de la Democracia como sistema político, social y económico, y que se caracterizó por aspectos tales como los problemas de legitimación de algunos regímenes autoritarios después de sufrir derrotas militares, como lo sucedido en las dictaduras de Argentina, Portugal, URSS y Grecia, aunque en los casos latinoamericanos, es más relevante la crisis de la deuda de los años 80s.

Por otra parte, el crecimiento económico mundial en los años sesenta con la consiguiente emergencia de clases medias urbanas en muchos países, contribuyó al desarrollo de una ciudadanía activa y participativa. También influirían, aunque de manera indirecta, los cambios producidos en la doctrina de la Iglesia Católica a partir del Concilio Vaticano II (1962-1965) y, más indirectamente en los casos latinoamericanos, la influencia del CELAM y la Teología de la liberación que se planteó la defensa de los derechos fundamentales de todo ser humano y se opuso a los regímenes autoritarios de Brasil, Chile, Filipinas o Polonia, principalmente, por su contribución a la violación de los derechos fundamentales de sus ciudadanos. Junto a lo anterior, destacarían la atracción ejercida por la Comunidad Económica Europea sobre muchos países, el giro de las políticas exteriores de los Estados Unidos con Carter (posterior a 1976) que buscaban la promoción de los Derechos Humanos y la Democracia, así como el desarrollo de la Perestroika de Gorbachov en la URSS (1986). Por último, lo que podemos definir como "Efecto bola de nieve" o "Efecto demostración”, que estimuló y proporcionó a otros países modelos o ejemplos de Transición. 
Por otra parte, diversos estudios historiográficos han establecido que las transiciones democráticas en España y América Latina pueden haber compartido algunas características básicas en cuanto a su desarrollo y proceso, debido a que en el plano político consistieron en tres tareas fundamentales. Primero, el desmantelamiento del antiguo Régimen autoritario a través del logro de acuerdos entre nuevas fuerzas políticas y la nueva institucionalidad. Segundo, la reconsideración del legado del pasado autoritario, referido al reconocimiento de las violaciones de los Derechos Humanos, por ejemplo, como un tema propio de la agenda de la Transición, como el caso Chile. Tercero, como todo nuevo sistema político, las nuevas instituciones democráticas requieren de legitimación, ámbito relacionado con la defensa, respeto y promoción de los derechos civiles y la libertad de todos los ciudadanos (Waisman et al., 2005).

En este aspecto, podemos entender que la construcción de una situación intermedia, es decir el tránsito a la Democracia, supone un equilibrio en la correlación de fuerzas entre los sostenedores del viejo régimen que se retiran o se adaptan y los partidarios de la recuperación de la Democracia que logran acceder a la dirección del Estado, luego de una negociación explícita o implícita y de acreditar electoralmente su respaldo en la sociedad (Maira, 1999), como sucedió en el caso chileno, a diferencia de otros procesos de Transición de América Latina, como las Dictaduras de Nicaragua y Argentina que caen principalmente por el desgaste del sistema autoritario (vía colapso), o el caso de Brasil que tiene que ver con la propia voluntad del régimen de avanzar en un proceso de Liberalización.

Uno de los elementos que se deben tener en cuenta al clasificar una Transición corresponden a las características del régimen político anterior; la justificación de la crisis que conduce al quiebre de los regímenes no democráticos; la estrategia seguida en el proceso de cambio, y el nuevo régimen establecido (la literatura ha usado tradicionalmente los conceptos alternativos pacto/colapso). Por ejemplo, en el caso español la tesis común responde a la descripción de un régimen peculiar, personalista, salido de una guerra civil; así la Transición no surge del colapso, sino de la necesidad de remplazar al jefe del estado, lo que se une a aspectos sociales y económicos, y a la "política de consenso" establecida entre Suárez y la oposición. De esta forma, se mantienen las leyes políticas, pero con un calendario de reforma; la Constitución se alcanzó por consenso sin presiones y el consenso se caracterizó por los pactos 
con empresarios y sindicatos; así la Democracia se consolidaría sin mayores problemas desde 1982 (Alcántara, 1992).

Desde algunos ámbitos de los estudios históricos, se ha criticado la insuficiencia de los modelos transitorios como referentes universales, debido a que la clasificación y evaluación de las transiciones quedaría subordinada al grado de cumplimiento. Esto ha tenido como consecuencia la elaboración de rígidos modelos de explicación teórica que muchas veces parecen haber estirado la evidencia empírica, para adaptarla al paradigma en cuestión. Por tanto, ignorar las diferencias cualitativas para reducir todo a un proceso idéntico es tanto como examinar la realidad subordinándola a un esquema teórico previo. La sociología histórica, en este caso, no está siendo esclava de la Historia, sino que la Historia está sirviendo de muralla contra los excesos abstractos de aquella (Díaz Gijón, 1996).

\section{Metodología}

En nuestro caso, la investigación se relaciona con dos de las tres categorías establecidas por Barton (2010) para los estudios sobre las ideas de los estudiantes acerca de la Historia, ya que pretendemos conocer lo que el alumnado chileno sabe sobre el pasado (la Transición) y cómo estructuran este conocimiento, para averiguar los orígenes del mismo, así como su relación con el currículo escolar y otras fuentes de información.

El objetivo general de la presente indagación consiste en: comprender las concepciones de los estudiantes de secundaria chilena sobre la Transición de la dictadura a la democracia en Chile, así como la valoración que hacen de este contenido escolar para su formación democrática y ciudadana. Específicamente, en este artículo nos centraremos en Analizar la opinión de los alumnos sobre cómo se produjo la Transición de una Dictadura a una Democracia en Chile, especialmente si la consideran como fruto de un proceso de acuerdos y consensos.

Como variable dependiente se centra en las opiniones que expresan los estudiantes, sobre la forma en cómo se produjo la transición hacia la democracia en nuestro país. En éste ámbito, se presta especial atención a los autores, las instituciones y los acontecimientos que los alumnos consideran que tienen una participación relevante dentro de la Transición, a la hora de exponer su 
discurso. En este sentido, dentro de las variables independientes consideramos el contexto Socio Económico (Tipo de Dependencia escolar: Municipal, Subvencionado y Particular), Género (hombres y mujeres) y el ámbito geográfico de aplicación (La Serena, Valparaíso, Santiago, Concepción).

El modelo elegido para esta investigación es una forma de muestreo sin probabilidad en la que se desconoce la probabilidad de selección. Por ello, se inserta dentro del denominado muestreo no probabilístico que se caracteriza porque la extracción de la muestra se efectúa siguiendo criterios diferentes de aleatorización (como la conveniencia u otros criterios subjetivos) (Cea D’Ancona, 2001). Así, entre las diferentes categorías de este tipo de muestreo, para esta investigación hemos seleccionado el tipo de muestreo por cuotas, el cual parte de la segmentación de la población de interés en grupos, a partir de variables socio-demográficas relacionadas con los objetivos de la investigación, por lo que su puesta en práctica conlleva una matriz con las características básicas de la población que se analiza. El propósito es seleccionar una muestra que se ajuste a la distribución de las características fundamentales de la población, para garantizar que en la muestra se encuentren representados los distintos grupos de población, lo que ayudaría a la realización de comparaciones entre ellos.

El estudio se aplicó a una muestra total de 616 alumnos en su aplicación final y se ejecutó en cuatro de las principales ciudades chilenas, considerando aquellas con mayor nivel de concentración de población y más cercanas a la zona central del país: La Serena, Valparaíso, Santiago y Concepción, ya que debido a sus características sociales, culturales y políticas, se pueden considerar representativas del país.

Se consideraron tres tipos de establecimientos educaciones tomando en cuenta, como ya hemos señalado anteriormente, las características socio-económicas de la población estudiantil que a ellos acude: Particular (Privado), Particular Subvencionado (Concertados) y Municipal (Públicos).

El instrumento de recolección de datos es un cuestionario elegido en nuestra investigación es el autorrellenable o auto determinado, puesto que se proporciona directamente a los respondientes, quienes lo completan sin mediación de intermediarios. Para este artículo hemos seleccionado una pregunta cerrada referida Señala el hecho o acontecimiento que consideras más importante del paso de la Dictadura a la democracia (Albert Gómez, 2007). 
Por último, el sistema de procesamiento estadístico de la información recogida se realizará por medio de un programa estadístico: el Statistical Package for the Social Sciences (SPSS), desarrollado por la universidad de Chicago, que permite el procesamiento fácil y útil de los datos cuantitativos. Su uso está generalizado en las investigaciones educativas y en las investigaciones en ciencias sociales, debido a que cubre todo el proceso analítico, desde la planificación hasta la presentación de resultados. De esta manera, podría ser definido como un paquete estadístico o conjunto de programas que implementan diversas técnicas estadísticas en un entorno en común (Martín, 2007).

\section{Hechos o Acontecimientos más importante DE La Transición Democrática}

Iniciamos este apartado trayendo de nuevo a colación a Braudel cuando escribió que rechazar los acontecimientos y el tiempo de los acontecimientos equivale a ponerse al margen, al amparo, para mirarlos con una cierta perspectiva, para juzgarlos mejor y no creer demasiado en ellos (Braudel, 1968), pues definen con exactitud nuestras pretensiones a la hora de analizar y estudiar el valor concedido por nuestros encuestados a los hechos que articulan el tiempo corto del proceso transicional.

Para escudriñar esa superficie de la comprensión histórica, pedimos a los estudiantes que señalaran el hecho o acontecimiento que consideraran más importante del paso de la dictadura a la Democracia. Dejando a un lado el importante volumen de alumnos que no contestan y los que marcaron varias opciones (Gráfico 1), los resultados nos demuestran que es la "Firma del Acuerdo Nacional para la Transición de la Plena Democracia” con un 39,8\% de las respuestas totales, la opción más elegida por los encuestados.

Las siguientes alternativas más marcadas son la "Creación de la Concertación de Partidos por la Democracia" [14,8\%], seguida por la "Promulgación de la Constitución de 1980" [7,5\%], el "Atentado contra Pinochet" $[6,2 \%]$ y el "Gobierno de la Concertación de partidos por la Democracia” [5,5 \%]. Por otro lado, llama la atención los bajos porcentajes asignados para las opciones representadas por los hechos como el "Arresto de Pinochet en Londres" [3,2\%], el "Asesinato del Senador Jaime Guzmán” 
Gráfico 1 - Señala el hecho o acontecimiento que consideras más importante del paso de la dictadura a la democracia

(Recuento de respuestas y porcentaje totales)

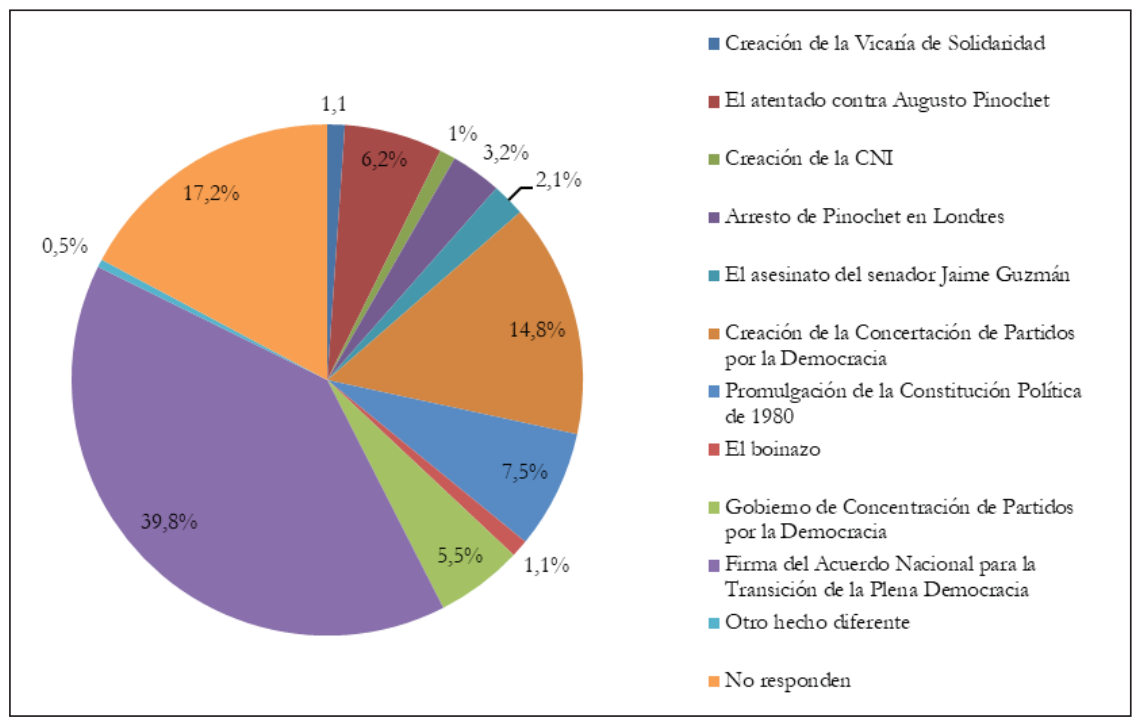

[2,1\%], el episodio militar del "Boinazo" [1,1\%], la "Creación de la vicaría de la Solidaridad" [1,1\%] y la "Creación de la CNI” [1 \%].

Si revisamos los resultados válidos comparados por género, podemos observar que se mantienen los mismos valores presentes en la descripción de la tendencia general referidos a la "Firma del acuerdo Nacional para la Transición" $[\mathrm{M}=51 \% \mathrm{H}=44,9 \%]$, la "Creación de la Concertación de Partidos por la Democracia" [M=15,6\% H=20,2\%], la "Promulgación de la Constitución de 1980" [M=9,5\% H=8,5\%] y el "Atentado de Pinochet" [M=7,2\% H=7,7\%].

La opción de la "Firma del Acuerdo para la Transición de la plena Democracia" se valora ligeramente más en los colegios particulares $[53,4 \%]$, por sobre los otros centros municipales [48,6\%] y subvencionados [46,4\%]. También existe coincidencia en la opción referida a la "Creación de la Concertación de Partidos por la Democracia” [CM=16,7\% CP=17,8\% CS= $18,4 \%]$. A las opciones antes descritas se agrega en tercer lugar, tal como sucede en el conteo general, la promulgación de la constitución política de 1980 pero solo para los centros particulares y subvencionados, pero no para los 
municipales donde pasa a ocupar un lugar irrelevante. En éstos la tercera opción más elegida es el atentado de Pinochet [9\%], lo que es muy interesante de hacer notar ya que, como hemos visto en otros casos, estos alumnos valoran hechos violentos y referidos al gobernador de facto.

En la sistematización de los datos por ciudades el esquema se repite con algunas diferencias. La alternativa referida a la "Firma del Acuerdo Nacional" es también la más valorada, oscilando entre el 51,5\% de Concepción y el 43,5\% de Santiago. Luego de esta opción, el porcentaje con más alta ponderación, al igual que en el recuento general, es para la alternativa la "Creación de la Concertación de Partidos por la Democracia”, excepto en La Serena [9,6\%] donde cede el segundo puesto a la opción Promulgación de la Constitución Política de 1980 [14,9\%]. Frente a estos resultados destacamos que aquí podría haber una valoración de un hecho de dictadura, más que de un acontecimiento de Democracia, situación que también puede relacionarse con que, para estos alumnos, de la Transición forma parte del itinerario del régimen. Esto debido a que este acontecimiento ocupa el tercer puesto en Concepción [11,5\%], pero no en Valparaíso ni en Santiago donde son más numerosos los alumnos que escogen El atentado a Pinochet, valorando la opción de aquellos que buscaban la caída de la dictadura por la vía insurreccional.

\section{La Firma del Acuerdo Nacional y la Creación de la Concertación}

Como hemos visto, las respuestas de los estudiantes señalan como hechos o acontecimientos sumamente relevantes del paso de la dictadura a la democracia la "Firma del Acuerdo Nacional para la Transición de la Plena Democracia" [39,8\%] y, aunque a más distancia la "Creación de la Concertación de Partidos por la Democracia" [14,8\%]. Ambas opciones nos indican una valoración del pacto y de la negociación entre las distintas fuerzas políticas para lograr el regreso de la democracia, lo cual resulta bastante sorprendente si contemplamos que en la evaluación de cómo se produjo la Transición, la mayoría de los alumnos la calificó como un proceso "violento" y sin embargo ahora no dudan en destacar la importancia de estos acuerdos.

Efectivamente, el primer hecho significó, en la práctica, un paso importante de diálogo y acuerdo entre el gobierno militar y la oposición mediado por la Iglesia Católica, al favorecer el encuentro de distintos líderes y representantes políticos que sentarán las bases para el retorno de la democracia. Para 
muchos estudiosos este encuentro representa la idea de un proceso transicional pactada, a pesar de que para los sectores afines a la dictadura no constituye un hecho trascendental para el regreso de la democracia.

En agosto de 1985 y a instancias de las gestiones moderadoras del Arzobispo Juan Francisco Fresno, un amplio espectro de partidos opositores se pusieron de acuerdo respecto a una serie de valores democráticos que debían regir la convivencia nacional y en un conjunto de medidas inmediatas para evolucionar efectivamente hacia la democracia. Nace así el acuerdo Nacional para la Transición a la Plena Democracia, un gran gesto de entendimiento profundo (en palabras del Arzobispo de Santiago Cardenal Fresno, principal gestor de esta actividad) constituyéndose en el hecho político más significativo desde que se iniciaran las movilizaciones sociales de protesta a comienzos de 1983 (Cañas Kirby, 1997).

La elección del Acuerdo Nacional por parte de los encuestados es muy interesante desde el ámbito curricular, ya que la firma del acuerdo no es un tema presente dentro del marco curricular escolar establecido, ni tampoco está considerado en los contenidos habituales de los libros de texto. Así mismo, desde la bibliografía muchos autores le quitan peso político e histórico a éste acontecimiento, es decir, tampoco hay un reconocimiento tácito de su importancia para la consecución del retorno a la democracia, ya que históricamente el proceso de diálogo se corta y el gobierno militar nunca lo reconoce un procedimiento válido para transitar hacia el sistema democrático.

A pesar de esto, la importancia de este documento radica en tres cuestiones. Primero, constituyó un símbolo preliminar de las necesidades, que ya se avizoraban en algunos sectores políticos de superar el escenario confrontacional, donde el único objetivo de la oposición era derrocar al régimen. Segundo, la iglesia asume el papel de institución convocante y mediadora, enlace entre los bloques políticos en pugna y no sólo de denuncia y defensa de los derechos humanos. Tercero, la coyuntura del acuerdo reunió por primera vez al más amplio espectro de partidos, desde la izquierda a sectores relevantes de la derecha, para lograr un acuerdo sobre temas conflictivos y que habían sido tabú para el régimen (Cañas Kirby, 1997).

De acuerdo con todo lo anterior, y en relación a nuestros estudiantes, nos queda la duda de si realmente consideran que la firma de este acuerdo tuvo una importancia capital para el retorno a la democracia y constituye el 
acontecimiento más relevante de la Transición chilena, o simplemente se han dejado llevar por el significado semántico de su denominación ("Firma del Acuerdo Nacional para la Transición de la Plena Democracia”). En cualquier caso, implica una valoración de los acuerdos entre élites políticas que entraría en contradicción con una visión mayoritaria de la Transición como fruto de las movilizaciones ciudadanas y de carácter violento. Y es que el Acuerdo Nacional ha sido la opción mayoritariamente elegida, no solo por los estudiantes que perciben el proceso transitorio como pacífico, sino también por los que lo definen como violento. ${ }^{2}$

Más lógica resulta la segunda selección más votada por los estudiantes que señala a la "Creación de la Concertación de Partidos por la Democracia" como el acontecimiento más relevante del periodo transicional, aunque también dentro de la línea contradictoria de conceder importancia a los consensos políticos. La Concertación fue creada el día 2 de febrero de 1988 cuando se conforma una agrupación en busca de la democracia, decidida a jugarse por el voto "NO". Este conglomerado reunía a diversos grupos políticos, que incitaron a toda la población opositora a inscribirse en los registros electorales con la finalidad de derrotar la dictadura por la vía del sufragio.

Recordemos que la anhelada Concertación de Partidos por el No, estaba compuesta por trece formaciones opositoras que tuvieron que negociar para conformar la reunión del Hotel Tupahue y firmar allí un manifiesto titulado "La oferta del NO”. El acuerdo proponía concentrar todas las energías en la inscripción en masa de electores y el triunfo del No en el Plebiscito. Además, el documento prometía para después de la victoria los reclamos más urgentes del club político opositor y de sus bases militantes: realizar elecciones libres; resolver los problemas más graves de derechos humanos; texto alternativo a la ley de partidos políticos; derogación del Art. $8^{\circ}$ de la Constitución; término del exilio... El que distintas colectividades políticas con historias tan diferentes lo aceptaran así, demostraba la desesperación que había cundido entre ellas para aprovechar la precaria oportunidad del '88 (Otano, 2006). La vía no confrontacional quedó abierta constituyendo, como dicen una parte importante de los encuestados, un acontecimiento fundamental de la Transición, ya que supuso la pérdida del poder del dictador con sus propias leyes y el acceso a la democracia. 
Hechos relacionados con Pinochet:

Promulgación de la Constitución y el Atentado

Los hechos destacados por nuestros estudiantes en tercer y cuarto lugar están relacionados con la figura del Dictador Pinochet, y corresponden con algunos acontecimientos desarrollados durante el gobierno militar tales como la "Promulgación de la Constitución de 1980" [7,5\%] y el "Atentado contra Pinochet" [6,2\%] ocurrido en 1986.

En primer lugar, debemos recordar que la promulgación de la Constitución política de 1980 marca el itinerario propuesto por el régimen, a través de los artículos transitorios, y define la Transición por medio del plebiscito de 1988. De esta manera cuando la oposición acepta la "legalidad constitucional", accede a las reglas del juego impuestas por la dictadura, admitiendo jugar en sus propias leyes. Y es que la Carta de 1980 llevaba en su interior dos constituciones, una contenida en su articulado transitorio que regulaba el periodo que iba desde marzo de 1981 hasta marzo de 1989. La otra en su articulado permanente suponía que debía durar muchas décadas a partir del fin del periodo anterior (Arriagada, 1998).

En este sentido, los estudiantes que seleccionaron la Constitución de 1980 como el hecho más relevante de la Transición parecen reconocer en el itinerario marcado por el dictador en su carta magna, la estructura fundamental del proceso, tal como recoge la historiografía afín al Régimen Militar. En este sentido resulta interesante comprobar que esta opción presenta un porcentaje bajísimo en los colegios municipales, cuyos alumnos no reconocerían este carácter al texto legal de 1980 .

En segundo término, el atentado a Pinochet se desarrolla en el contexto del denominado "año decisivo" en la lucha contra el dictador. Los autores jamás imaginaron el provecho político que sacaría Pinochet del atentado contra su vida, que no fue el primero pero si el más espectacular de los realizados en su contra. Obra del Frente Patriótico Manuel Rodríguez, consolidó en el general la idea de ganar el reconocimiento de la comunidad internacional y de seguir ininterrumpidamente el itinerario de 1980 (Gazmuri, 2000).

El atentado finalizó con la idea de vencer al dictador por medio de la vía armada, línea de acción del partido comunista a través de su brazo armado, el denominado Frente Patriótico Manuel Rodríguez, y el reconocimiento por parte de la oposición de la carta constitucional de 1980 y el conocido Plan 
Aylwin, estrategia de derrotar a Pinochet en su propia ley, es decir, la vía constitucional a través del plebiscito de1988.

Por tanto, nos queda la duda de si los estudiantes que escogieron esta opción como acontecimiento relevante, lo hicieron desde la perspectiva de ensalzar la lucha revolucionaria o desde la óptica de resaltar la vía de la concertación y el diálogo. Si tenemos en cuenta los datos cruzados entre los que escogen esta alternativa y las opciones de violenta o pacífica podemos observar que entre los porcentajes presentados en la tendencia general los alumnos que marcan la alternativa Atentado a Augusto Pinochet habiendo marcado en la pregunta sobre cómo se produjo el paso a la Democracia la opción de "Pacífica", son más numerosos que los alumnos que marcan la característica de "Violenta".

También es importante considerar que la votación por la alternativa referida al "Atentado a Augusto Pinochet" tiene un porcentaje más elevado entre los alumnos que consideran que "Augusto Pinochet" es un actor relevante dentro del proceso de Transición, y un porcentaje bastante inferior entre los que marcan "Oposición política”. ${ }^{4}$

\section{Hechos ocurridos durante los Gobiernos de la Concertación}

En nuestro cuestionario, incluimos como posibles hechos más relevantes de la Transición, de entre los cuales debían escoger los estudiantes aquel más significativo, algunas efemérides de los primeros años de la Concertación, como el propio Gobierno de la Concertación de Partidos por la Democracia, el asesinato del Senador Jaime Guzmán, el Boinazo y el arresto de Pinochet en Londres. Frente a estas alternativas, llama la atención los bajos porcentajes asignados para las opciones representadas por los hechos como el Boinazo $[1,1 \%]$, Arresto de Pinochet en Londres [3,2\%] y finalmente Asesinato de Jaime Guzmán [2,1\%].

Como ya hemos indicado, la Concertación por la Democracia, sucesora de la coalición que se uniera en el plebiscito del 88 para derrotar a Pinochet bajo el nombre de Partidos por el No, representaba a un conglomerado político que reunía inicialmente 16 partidos o grupos de diferentes espectros políticos y que, con algunas variables, se prolongaría como base política de los gobiernos democráticos posteriores desarrollados entre los años 1990-2010.

Así la Concertación se convierte en la coalición que gobernó Chile desde el retorno de la Democracia hasta el año 2010, cuyo sostén estuvo basado en una 
elaborada fórmula de distribución del poder, a partir de la negociación de las carteras ministeriales, de las subsecretarías e incluso de la distribución de los candidatos legislativos de los distintos sectores que la constituyen, situación que responde a una visión de la política basada en el acuerdo y la participación de todos los sectores que apoyan al gobierno, manteniendo así la coalición (Siavelis, 2009). ${ }^{5}$

Esta forma de gobierno representa, pues, la valoración del acuerdo, ya que la creación de la Concertación significa sentarse y entenderse. Esta situación es percibida por el [5,5\%] de estudiantes que escogieron el "Gobierno de la Concertación de partidos por la Democracia” como acontecimiento más relevante de la Transición, para los cuales la búsqueda del acuerdo para lograr la Democracia constituiría un aspecto clave para canalizar la lucha ciudadana y asegurar su éxito.

Un hecho importante que marcó el desarrollo de los gobiernos concertacionistas está referido al asesinato del Senador Jaime Guzmán Errázuriz, colaborador y defensor fehaciente del régimen militar y de la figura de su dictador, participante en la redacción de la Constitución de 1980 y fundador del partido de derecha Unión Demócrata Independiente. Para la opinión pública Guzmán representaba el protector y defensor incondicional de Pinochet, como el legitimador a ultranza de su gobierno. Además, sus adversarios no podían creer que una persona tan interiorizada con el régimen no conociese lo que estaba sucediendo durante años en sus cloacas más represivas. A pesar de haber flexibilizado tácticamente desde el advenimiento de la democracia, su máquina silogística que descargaba aseados argumentos para justificar los "males menores" del régimen, no incluía en su discurso el dolor de tantas personas inocentes, a quienes no se les había reconocido ni sus muertos (Otano, 2006). Su asesinato ocurrió el día 1 de abril de 1991 a causa de un atentado perpetrado por integrantes del grupo terrorista denominado Frente Patriótico Manuel Rodríguez, el brazo armado del Partido Comunista, la misma agrupación autora del atentado a Pinochet en 1986, la que constituye para un [2,1\%] de alumnos el momento más importante del proceso de Transición chilena, que buscaban derribar al gobierno por la vía de las armas. Como vemos esta situación resulta significativa para este pequeño grupo de estudiantes, que han valorado la vía de la insurrección armada para finalizar la dictadura, como una forma válida de lucha.

El otro hecho que determinó el desarrollo de la Transición y tensionó las relaciones cívico-militares, está referido al incidente denominado como el 
"boinazo", es decir el paseo por la Alameda de las boinas negras del Ejército Nacional. Este episodio se origina a partir del sentimiento declarado por los militares como "hostigamiento contra el Ejército" que habría ejercido el diario La Nación. Más allá de los detalles, esta situación representó la fragilidad de nuestro sistema democrático, la fuerte presencia de los militares en la vida pública del país y la autoridad ejercida por Pinochet. Así las boinas negras presentes en la Alameda, con rostros afilados y premunidos de corvos y lanzacohetes LAW, negaban esta idílica imagen de la gloriosa transición. El ejército no se había modernizado tanto como se pensaba (Otano, 2006). A diferencia de lo que el mismo Aylwin pensaba y que había expresado en el mensaje presidencial del 21 de mayo de 1993, donde reconocía con orgullo la trayectoria que había seguido el país valorando la forma en que se había desarrollado el paso hacia la normalidad democrática de forma pacífica, ${ }^{6}$ los militares mantenían cierto poder en el mundo civil y no estaban dispuestos a irse a sus cuarteles sin que les garantizaran tranquilidad. Por tanto, la importancia de este episodio militar ocurrido en 1993 y que es recogida por un 1,1\% de los encuestados, señala esta idea que a pesar del carácter pacífico de la recuperación democrática, los militares mantenían una fuerza que no tenían problemas en exponer, en caso que ellos lo consideraran necesario.

Por último, otro episodio significativo dentro de los primeros años de los gobiernos en democracia es el referido a la detención del ex dictador en Inglaterra, reconocido como hecho fundamental por una parte de nuestros estudiantes [3,2\%]. Efectivamente, cuando el día 16 de octubre de 1998 Pinochet fue detenido en Londres, un sentimiento colectivo de justicia recorrió el mundo. La razón alegada para la solicitud de extradición era "por delito de terrorismo, genocidio y tortura”. Así se produjo el hecho que más desbarató el proceso ultra regulado de la Transición. La noticia de un Pinochet detenido en Londres y posiblemente extraditado a Madrid reveló la fragilidad de los supuestos y de los implícitos de la política chilena postdictadura. Para los simpatizantes del general la consecuencia más demoledora del proceso de Londres fue el reconocimiento, por parte de su defensa, de las torturas y asesinatos perpetrados durante el régimen militar. Esta forzada confesión pública marcó silenciosamente un antes y un después en la opinión de los partidarios de la dictadura. Ya nadie en adelante podía alegar ignorancia de tanta barbarie (Otano, 2006). Por tanto, el arresto significó para muchas personas indecisas 
respecto a la valoración del régimen dictatorial, reconocer la violación a los Derechos Humanos durante este tiempo.

En este sentido, entendemos importante señalar que la elección del "Arresto de Pinochet en Londres" tiene un porcentaje bastante más elevado entre los que declaran el rol preponderante de las "Fuerzas Armadas" y un porcentaje inferior entre los que imprimen su opción de "Partidos políticos" como actores importantes dentro proceso transitorio. ${ }^{7}$

De manera que al hacer una comparación entre las respuestas que evalúan la Transición (violenta o pacífica) y los acontecimientos más importantes de este proceso, podemos observar que existe una diferencia entre aquellos estudiantes que marcan la alternativa "Violenta" frente a los que marcan "Pacífica", ya que los primeros presentan una mayor valoración de las opciones referidas al "Arresto de Pinochet en Londres" [89,5\% frente a 10,5\%] y Atentado de Augusto Pinochet [77,4\% frente a 22,6\%] como los hechos o acontecimientos que consideraron más importante del paso de la Dictadura a la Democracia. Es decir, los que valoran la Transición como violenta destacan los hechos relacionadas con la figura gobernador de facto ${ }^{8}$ situación que podría representar como la figura de Pinochet es relevante no solo en la Dictadura, sino que también durante el proceso de retorno a la Democracia.

\section{Hechos vinculados a los Derechos Humanos}

Las respuestas de nuestros estudiantes indican bajas ponderaciones para dos hechos relacionados con elementos claves de la Dictadura y la violación de los derechos humanos y que tienen que ver con la Creación de la Vicaría de la Solidaridad [1,1\%] y la Creación de la CNI [1\%]. La escasa importancia atribuida a la primera resulta contradictoria con las respuestas entregadas por los encuestados cuando se les interroga sobre los temas más abordados en clase, donde, como veremos en el siguiente capítulo, un porcentaje importante de nuestros chicos y chicas destacan el rol de la iglesia y la violación de los derechos humanos.

A partir del caso Letelier en 1976, la DINA (Dirección de Inteligencia Nacional) fue reemplazada por otra policía, de carácter menos brutal, la Central Nacional de Informaciones (CNI). Esta institución fue un organismo de inteligencia de gran influencia dentro del gobierno militar, responsable de importantes casos de violación de los derechos fundamentales de los ciudadanos, como asesinatos, secuestros y tortura de personas. 
Frente a estos actos, la actitud de la iglesia evolucionó hacia posturas más divergentes que desembocaron en una patente contraposición entre las pretensiones del gobierno y los principios básicos de la doctrina social de la iglesia. En efecto, hubo tres ejes que le otorgaron sustento a su actitud divergente con el gobierno militar: la violación de los derechos humanos, la orientación individualista y excluyente de la política económica y la pretensión de la autoridad de buscar en la doctrina social elementos de legitimación ética de su acción. La Iglesia Católica asume, así, un claro papel político, transformándose en una especie de partido moral de la sociedad. Con la creación de la Vicaría de la Solidaridad a fines de 1975, no sólo denuncia públicamente la violación de los derechos humanos, sino que reconoce a los demás actores sociales, especialmente a los partidos y les brinda protección y canales de acción para sus tareas en la sociedad civil (Cañas Kirby, 1997).

La Vicaría de la Solidaridad, al alero de la Iglesia Católica, se transformó en el refugio y defensa de los perseguidos políticos y la única institución que se atrevió a enfrentar a la DINA y abogar abiertamente contra la violación de los derechos humanos (Gazmuri, 2000). La acción de la Vicaría se desarrolló a través de diversas distintas organizaciones sociales, parroquias y lugares de reunión del mundo católico, que centraba su actividad en asuntos de solidaridad y promoción de la dignidad humana. Así movimientos juveniles, centros culturales, comités de familiares de desaparecidos, cooperativas de obreros y campesinos, se convirtieron en espacios de articulación de diversos sectores políticos. Según un ministro de Estado de la Dictadura, la Vicaría de la Solidaridad se convirtió en una organización de contrainteligencia, manejada con el objetivo político de derrocar al régimen y brindar al terrorismo una cobertura moral y logística que necesitaba (Gazmuri, 2000). ${ }^{9}$

\section{Consideraciones finales}

En este sentido hemos comprobado que el paso de la dictadura a la democracia es entendida por el estudiantado a partir de la participación de actores sociales más que políticos. Enfatizan la relevancia jugada por los ciudadanos y los movimientos sociales, aunque también a una cierta distancia por los partidos políticos y la oposición, quienes gestionan y hacen posible el retorno de la Democracia, mediante el desarrollo de manifestaciones o protestas en contra 
del régimen de facto (en el caso de los primeros) y de su reorganización (en el caso de los segundos). Valoran positivamente, y como situación culminante de este proceso de lucha ciudadana para la consecución de la democracia, la realización del referéndum del 5 de octubre de 1988 y la derrota del dictador en este proceso eleccionario.

\section{REFERENCIAS}

ALBERT GÓMEZ, María José. La investigación educativa: claves teóricas. Madrid: McGraw Hill, 2007.

ALCÁNTARA, Manuel. Las transiciones a la democracia en España, América Latina y Europa Oriental. Elementos de aproximación a un estudio comparativo. Revista del Centro de Estudios Constitucionales, v.11, p.10-14, ene./abr. 1992.

ARRIAGADA, Genaro. Por la razón y la fuerza: Chile bajo Pinochet. Santiago: Sudamericana, 1998.

BARTON, Keith. Investigación sobre las ideas de los estudiantes acerca de la Historia. Revista Enseñanza de las ciencias sociales, v.9, dic. 2010.

BRAUDEL, Fernand. La Historia y las Ciencias Sociales. Madrid: Alianza, 1968.

CAÑAS KIRBY, Enrique. Proceso Político en Chile: 1973-1990. Santiago: Ed. Andrés Bello, 1997.

CEA D’ANCONA, Maria Ángeles. Metodología cuantitativa: estrategias y técnicas de investigación social. Madrid: Síntesis, 2001.

DÍAZ GIJÓN, José Ramón. Estrategias de análisis y modelos de transición a la democracia. In: TUSELL, Javier; SOTO, Álvaro (Ed.) Historia de la transición: 19751986. 2.ed. Madrid: Alianza, 1996.

FAÚNDEZ, Gloria. Carta transversal sub 40 pide "esfuerzo colectivo para reconciliación”. Diario La Tercera, Grupo Editorial Copesa, 11 sep. 2013. Disponible en: http:// diario.latercera.com/edicionimpresa/carta-transversal-sub-40-pide-esfuerzo-colectivo-para-reconciliacion/; acceso el: 13 sep. 2013.

GAZMURI, Cristián. La persistencia de la memoria: reflexiones de un civil sobre la dictadura. Santiago: Ril, 2000.

GONZÁLEZ GALLEGO, Isidoro. La transición: realidad del pasado y revisionismo del presente. Revista Íber - Didáctica de las Ciencias Sociales, Geografía e Historia, v.67, ene./feb./mar. 2011.

HUNTINGTON, Samuel. La tercera ola: la democratización a finales del siglo XX. Barcelona: Paidós, 1992. 
IGLESIAS, Ricardo. El Papel de la educación en la construcción del Estado Nacional. In: CID, Gabriel; SAN FRANCISCO, Alejandro (Ed.) Nación y nacionalismo en Chile, siglo XIX. Santiago: Centro de Estudios Bicentenario, 2009. p.50.

MAIRA, Luis. La transición interminable. México, D.F.: Grijalbo Hojas nuevas, 1999.

MARTÍN, Quintín. Tratamiento estadístico de datos con SPSS: prácticas resueltas y comentadas. Málaga: Paraninfo, 2007. p.2-6.

O'DONNELL, Guillermo; SCHMITTER, Philippe. Transiciones desde un gobierno autoritario. Tomo 4, Conclusiones tentativas sobre las democracias inciertas. Buenos Aires: Paidós, 1998. p.19-20.

OTANO, Rafael. Nueva crónica de la transición. Santiago: LOM, 2006.

SIAVELIS, Peter. Enclaves de la transición y democracia chilena. Revista de Ciencia Política, Santiago, v.29, n.1, 2009.

TUSELL, Javier; SOTO, Álvaro (Ed.) Historia de la transición: 1975-1986. Madrid: Alianza, 1996.

VENTURA, Dalia. Por qué el golpe de Estado en Chile es tan emblemático. BBC Mundo Noticias. Disponible en: http://www.bbc.co.uk/mundo/noticias/2013/09/130906_chile_11_septiembre_golpe_emblematico.shtml; acceso el: 11 sep. 2013.

WAISMAN, Carlos; REIN, Raanan; GURRUTXAGA, Ander (Comp.) Transiciones de la dictadura a la democracia: casos de España y América Latina. Bilbao: Ed. Universidad del País Vasco, 2005.

\section{NOTAS}

${ }^{1}$ Se recomienda revisar el artículo periodístico VENTURA, 2013.

${ }^{2}$ Datos obtenidos del análisis de la tabulación cruzada entre la pregunta referida a ¿Cómo consideras que se produjo el paso de la Dictadura a la democracia en nuestro país? y la de Señala el hecho o acontecimiento que consideres más importante del paso de la Dictadura a la democracia.

${ }^{3}$ Datos obtenidos del análisis de la tabulación cruzada entre las preguntas referidas a ¿Cómo consideras que se produjo el paso de la Dictadura a la democracia en nuestro país? / Señala el hecho o acontecimiento que consideres más importante del paso de la Dictadura a la democracia.

${ }^{4}$ Datos obtenidos del análisis de la tabulación cruzada entre la pregunta referida a ¿Quiénes de los siguientes actores o instituciones permitieron el paso de una Dictadura a una democracia en nuestro país? y la de Señala el hecho o acontecimiento que consideres más importante del paso de la Dictadura a la democracia. 
${ }^{5}$ La forma de distribución del poder que se conoce como "cuoteo". Los detalles de esta negociación incluyen una cuidadosa división de carteras ministeriales entre sus partidos constituyentes. Los subsecretarios han sido, en general, de un partido diferente (y usualmente de un sector ideológico distinto) que el del ministro. Si bien no existe un acuerdo formal de tal arreglo, la institución informal de entrada de los partidos, extendida en la toma de decisiones ministerial, ha proporcionado un incentivo para el mantenimiento de la coalición. Lo que es más, a lo largo de los ministerios, y en particular en los ministerios "políticos", cada administración postautoritaria procuró proporcionar una representación completa de los partidos políticos que integran la Concertación en personales de nivel superior. Estos acuerdos caracterizan la mayor parte de la administración pública e incluso se extienden a la distribución de los escaños de los candidatos legislativos. Las diferentes facciones partidistas, dentro de la coalición, también apelan al presidente para situar a una serie de funcionarios de cada una de las facciones en posiciones de poder en toda la rama ejecutiva y en otras áreas en las que el presidente realiza nominaciones.

6 "Debe ser motivo de legítima satisfacción para los chilenos, especialmente para los que tenemos responsabilidades en la conducción de nuestra patria. La forma como ha transcurrido la vida política, económica y social del país en este período. El tránsito del largo lapso de régimen autoritario al funcionamiento normal de nuestra convivencia democrática ha tenido lugar sin traumas ni quebrantos. Chile vive en paz. La gente goza de libertad. El país progresa. Nuestra estabilidad política, nuestro crecimiento económico y nuestro desarrollo social suscitan elogios en el exterior." Citado en OTANO, 2006, p.259260. Versión original: Mensaje Presidencial Legislatura 326a, Ordinaria, Sesión del Congreso Pleno, en viernes 21 mayo 1993. Disponible en: http://www.camara.cl/camara/ media/docs/discursos/21mayo_1993.pdf.

${ }^{7}$ Datos obtenidos del análisis de la tabulación cruzada entre las preguntas referidas a ¿Quiénes de los siguientes actores o instituciones permitieron el paso de una Dictadura a una democracia en nuestro país? / Señala el hecho o acontecimiento que consideres más importante del paso de la Dictadura a la democracia.

${ }^{8}$ Datos obtenidos del análisis de la tabulación cruzada entre las preguntas referidas a ¿Cómo consideras que se produjo el paso de la Dictadura a la democracia en nuestro país? /Señala el hecho o acontecimiento que consideres más importante del paso de la Dictadura a la democracia.

${ }^{9}$ Citado originalmente en El Mercurio, 31 dic. 1987.

Artículo recibido el 19 de octubre de 2018. Aprobado el 23 de octubre de 2018. 